\title{
CONCRETIZAÇÃO DOS DIREITOS FUNDAMENTAIS POR MEIO DA ATIVIDADE EMPRESARIAL
}

\author{
Alexandre Augusto Rocha Soares ${ }^{1}$ \\ Pedro Durão ${ }^{2}$
}

RESUMO: A concretização dos direitos fundamentais é objetivo perseguido pelo ordenamento jurídico brasileiro hodierno. Todos os atores, públicos e privados, devem voltar suas ações para esta finalidade e, mais especificamente, para a dignidade da pessoa humana, dentro de um contexto em que se debate o papel do empreendedorismo e a suposta adoção de um Estado de Responsabilidade Social. Neste artigo, busca-se depreender a norma constitucional que embasa tais afirmações, tendo por objetivos específicos a análise do papel do empreendedorismo e a reflexão acerca da necessidade de atuação dos agentes privados.

Palavras-chave: direitos fundamentais; eficácia horizontal e diagonal; estado de responsabilidade social; empreendedorismo; cidadania corporativa.

\section{THE CONCRETIZATION OF FUNDAMENTAL RIGHTS BY THE BUSINESS ACTIVITY}

ABSTRACT: The realization of fundamental rights is an objective pursued by today's Brazilian legal system. All actors, public and private, should turn their actions towards this purpose and, more specifically, to the dignity of the human person, within a context in which the role of entrepreneurship and the supposed adoption of a State of Social Responsibility are debated. In this article, we seek to understand the constitutional norm that supports these statements, with the specific objectives of analyzing the role of entrepreneurship and reflecting on the need for action by private agents.

Keywords: fundamental rights; horizontal and diagonal effectiveness; state of social responsibility; enterpreneurship; corporate citizenship.

\section{INTRODUÇÃO}

O papel do empreendedorismo na construção de um mundo ideal não é construção utópica, nem ideológica. Trata-se de uma necessidade diante do vulto tomado pela atividade

\footnotetext{
${ }^{1}$ Mestrando em Direito Constitucional pela Universidade Federal de Sergipe (UFS). Especialista em Direito Processual pela Pontifícia Universidade Católica de Minas Gerais (PUC-MG). Graduado em Direito pela PUCSP e em Jornalismo pela Universidade de São Paulo (USP). Procurador do Estado de Sergipe e advogado.

2 Pós-doutor em Direito pela Universidad de Salamanca (Espanha). Doutor e Mestre em Direito. Procurador do Estado de Sergipe. Professor Adjunto da Universidade Federal de Sergipe (UFS). Investigador perante o Grupo de Pesquisa Dimensions of Human Rights do Instituto Jurídico Portucalense (IJP-UPT). Advogado, consultor e parecerista.
} 
empresarial e da incapacidade dos governos em responderem adequadamente às demandas sociais.

Neste cenário pouco inspirador, a concretização de direitos fundamentais por meio da atividade empresarial surge como alternativa econômica, jurídica e socialmente viável para responder aos desafios impostos pelo capitalismo oligopolista, sem negá-lo, mas se utilizando de ferramentas para fazê-lo mais humano e condizente com as necessidades sociais.

A concretização dos direitos fundamentais é dever de todos os atores sociais no contexto contemporâneo. Para além da ilação de que caberia ao Estado prover todo o bem necessário aos indivíduos, a conformação da economia global neste século demanda a atuação firme e consciente de empresas, que detém ação coordenada internacionalmente, para o bem comum, dadas as vastas proporções que seus negócios adquiriram. A necessidade da atuação privada na concretização de direitos fundamentais é exigência de ordem prática para a sobrevivência do ser humano enquanto espécie.

O reconhecimento destas potencialidades é que demanda, do Direito Empresarial, uma releitura e uma ressignificação, tornando-o mais apropriado ao atual regime constitucional, ainda que se trate de leitura implícita da Carta - mormente porque aos Direitos Fundamentais deve ser dada leitura ampliativa. O Direito Empresarial não é um ramo do Direito voltado exclusivamente ao bem-estar de seus sócios, mas de todos aqueles que interagem direta e indiretamente com a atividade empresarial, como clientes e empregados.

Daí deflui a função social da empresa e a necessidade de desenvolver mecanismos para que, voluntariamente, se produza em favor da sociedade, sem perder de vista o papel da empresa numa sociedade capitalista, mesmo porque o lucro é necessário e desejável para o desenvolvimento econômico, com o social vindo à reboque.

Esta problemática - a falta de responsividade dos Estados-nação somado ao potencial transformador das empresas para a concretização dos direitos fundamentais - coloca como desafio principal como se utilizar das ferramentas já existentes, como sanções premiais, em instrumentos para a concretização de direitos.

O objetivo geral deste trabalho é discutir alternativas jurídicas para esse desafio, especificamente como o empreendedor precisa ser protegido dele mesmo e como a socialização dos ganhos da atividade é necessária para o bem geral, inclusive do próprio empresário. Como objetivos específicos, buscará refletir sobre a necessidade de mecanismos eficazes de indução do comportamento empresarial e do papel do Estado. 
A pesquisa foi essencialmente bibliográfica, tomando como base a subsunção entre as afirmações e interpretações hodiernas da Constituição Federal em face das necessidades do mundo moderno, com que se espera contribuir para que a proposta saia do plano teórico para o prático, sem ideologias. Os principais referenciais teóricos foram as obras de Ingo Sarlet, Flávia Piovesan, Eros Grau e Luis Roberto Barroso.

\section{Da concretização de direitos como dever de todos}

O robustecimento da economia empresarial globalizada ${ }^{3}$ nas três últimas décadas constitui desafio para o Direito, posto que for a acompanhada de potencialidades e de riscos antes inexistentes. São os atores privados os verdadeiros detentores do poder na contemporaneidade, não mais os Estados-Nação - o controle e o aparelhamento do Estado são meros instrumentos do empresariado para ampliar ainda mais seu poder ${ }^{4}$. As empresas transnacionais podem contribuir decisivamente para impactos sociais expressivos com seu poderio financeiro e eficiência, ainda que, nas última décadas, elas tenham se notabilizado por grandes desastres socioambientais, como rompimento de barragens, migrações em massa, entre outros, bem como tenham assumido indevidamente o protagonismo político (WARDE JÚNIOR, 2008).

Os impactos sobre os direitos humanos, portanto, tem participação decisiva das empresas, donde emerge a necessidade delas mesmas mitigarem e sanarem esses riscos, as violações de direitos, já que são os vulneráveis quem mais sofrem com os ilícitos. Os ordenamentos jurídicos não devem admitir os bônus (lucros) sem que deles advenham ônus (responsabilidade e justiça social).

3 RUGGIE (2013, p. 17) define a globalização como o fenômeno de reestruturação produtiva e da atuação internacional coordenada de corporações transnacionais.

4 As empresas não devem, ontologicamente, ter atuação na política, que deveria respeitar o primado da cidadania exclusivo das pessoas naturais - exatamente por isso, o STF vetou a contribuição empresarial para campanhas político-partidárias na ADI n. 4650 (STF - ADI: 4650 DF, Relator: Min. LUIZ FUX, Data de Julgamento: 26/03/2013, Data de Publicação: DJe-059 DIVULG 01/04/2013 PUBLIC 02/04/2013). No entanto, a visão de que o controle dos meios estatais permite ampliar os lucros empresariais leva muitos empreendedores a atuar politicamente para inflar seus lucros. As empresas desviam sua atuação econômica para ter um papel político. Esta temática é explanada em artigo de Walfrido Warde Jr (WARDE JUNIOR, Walfrido Jorge. A empresa pluridimensional : empresa política e lobby. Revista do advogado, São Paulo, a.28n.96 (Jul.2008), p.137-145). 
A dignidade da pessoa humana ${ }^{5}$ - vetor axiológico máximo da Constituição Federal informa todos os outros princípios, sendo meio e fim de toda a atividade perpetrada em território nacional, inclusive as empresariais ${ }^{6}$. Não se admitem condutas tendentes a aniquilálas, ao passo em que todos os esforços para concretizá-la e incentivá-la devem ser travados por atores públicos e privados para lhes emprestar máxima efetividade.

A dignidade da pessoa humana é fundamento da atividade econômica, é sua razão de ser da (BARROSO, 2008). Do cotejo dessas normas em favor da dignidade da pessoa humana e do capitalismo adotado pela Carta, há estudiosos que apontam para a suposta adoção de um capitalismo mais responsável pelo constituinte. Na iminente escola de direito da Pontifícia Universidade Católica de São Paulo (PUC-SP), por exemplo, há estudos de relevo acerca do que seria um "capitalismo humanista"7. SAYEG e BALERA (2011), dois percurssores da teoria, afirmam que a Carta adotou essa concepção ao colocar, lado a lado, no art. 170, a livre iniciativa, a dignidade da pessoa humana e a justiça social.

Apesar da propriedade privada ser o centro da atividade econômica, direito fundamental de todos em território nacional, a dignidade da pessoa humana permeia a cadeia produtiva, que tem por fim último garantir a justiça social, promovendo o bem-estar de todos que dela participam direta ou indiretamente, como donos dos meios de produção (GRAU, 2007), trabalhadores, consumidores, fornecedores, entre outros. Assim, apesar do lucro ser desejável e protegido, não deve ele ser obtido a qualquer custo (BARROSO, 2008). Deve haver um necessário equilíbrio entre o bem-estar do dono, que deseja maximizar seus ganhos, e da sociedade, que não deve ser sacrificada ${ }^{8}$.

Esse é o "fio condutor" para que se conectem os fins meramente econômicos do liberalismo puro smithiano e valores como solidariedade e redistribuição de renda. A atividade empresarial é um instrumento para que se promova a dignidade, seja de sócios, empregados,

5 SARLET $(2004$, p. 61$)$ assim define: “(...) por dignidade da pessoa humana a qualidade intrínseca e distintiva de cada ser humano que o faz merecedor do mesmo respeito e consideração por parte do Estado e da comunidade, implicando, neste sentido, um comple-xo de direitos e deveres fundamentais que assegurem a pessoa tanto contra todo e qualquer ato de cunho degradante e desumano, como venham a lhe garantir as condições existenciais mínimas para uma vida saudável, além de propiciar e promover sua participação ativa e corresponsável nos destinos da própria existência e da vida em comunhão com os demais seres humano (...)".

6 Esta é a linha mestra das obras de PIOVSAN (2018) e DURÃO (2018).

7 Segundo os adeptos dessa corrente, trata-se de uma visão do capitalismo que equilibra valores econômicos e sociais, ou seja, modificando a concepção do mercado como terrível e desumano para uma visão humanizada, para satisfação dos direitos fundamentais e cultivar a paz.

8 O direito à sustentabilidade empresarial está implícito na Carta, convolando-se portanto em direito subjetivo do cidadão, considerando-se, ainda, o rol exemplificativo de direitos no art. 5. 
clientes ou fornecedores. Tudo o que gira em torno da atividade empresarial deve ter por norte a dignidade da pessoa humana (PIOVESAN, 2018; DURÃO, 2018) - o lucro, além de mera consequência, é estímulo para que se persigam tais objetivos por meio da atividade empresarial. Ressalte-se, todavia, que a eliminação de um ou outro não é aceitável no atual ordenamento.

Todo o Direito Empresarial deve ser lido após a filtragem ${ }^{9}$ exigida pela Constituição (GRAU, 2007), tornando-o mais humano e condizente com a realidade nacional, em especial no que se refere à responsabilidade sócio-ambiental. A autonomia da vontade "pura" foi substituída por outra, temperada por valores humanísticos, com reflexos severos na formação, execução e extinção dos contratos (SAYEG e BALERA, 2011).

\section{Da horizontalidade da eficácia dos direitos fundamentais}

Apesar do direito fundamental proposto estar dentro do escopo da fraternidade e solidariedade, entende-se que a contemporaneidade, dado o relevo da questão, demanda a superação da discussão acerca das dimensões de direitos ${ }^{10}$ para avançar na problemática.

Este ramo do Direito, atualmente, reconhece a eficácia externa dos contratos e toda sua potencialidade para cumprir com seus deveres constitucionais. Isto não significa fazer filantropia, pois responsabilidade social não se confunde com a função social da empresa: ao realizar sua atividade econômica de modo responsável, aquela projeta efeitos positivos por toda a sociedade, promovendo ganhos de escala e benefícios sociais que vão para muito além de seus muros ${ }^{11}$.

As pessoas jurídicas, há muito, deixaram de ser um patrimônio constituído no absoluto interesse dos sócios. O Direito lhe confere existência, vida próprias; nesse sentido, interage com os diversos atores dentro da sociedade, modifica a realidade a seu redor, mesmo que para isso precise do auxílio dos prepostos. Quer dizer, o projeto a ser desenvolvido buscará depreender o alcance das normas para refutá-la ou confirmá-la. Os Direitos Fundamentais devem atender a toda a coletividade, sem perder de vista a essência das pessoas jurídicas.

9 A expressão filtragem constitucional é atribuída ao jurista português Gomes Canotilho.

10 Os direitos de primeira dimensão são aqueles ligados às liberdades negativas; os de segunda dimensão, aquelas ligados à igualdade material e a prestações positivas; finalmente, os de terceira dimensão escancaram a fraternidade e solidariedade. Há autores que vão para além destas dimensões, não havendo consenso sobre elas.

11 Esses compromissos já são aceitos internacionalmente desde 2011, embora ainda não existam meios coercitivos para exigir o cumprimento pelos Estados. 
A eficácia dos Direitos Fundamentais ${ }^{12}$ é tema a ser enfrentado sob múltiplas perspectivas: da verticalidade, da imediatidade, da titularidade, entre outros. Para além da mera disposição constitucional, que enuncia sua eficácia imediata e integral, há de se ponderar até que ponto essa afirmação é verdadeira, notadamente quanto aos direitos prestacionais. Há, ainda, a problemática da aplicação dos direitos fundamentais às pessoas jurídicas, tendo em vista que, teleologicamente, foram idealizados para a proteção das pessoas naturais - e, aqui, afirma-se na aplicabilidade da norma tanto como beneficiários quanto como responsáveis pela concretização, exigindo-lhe posturas ativas e efetivas.

Analise-se, primeiramente, quanto à verticalidade. Embora seja, no nosso sentir, impreciso catalogar os direitos fundamentais dentre gerações ${ }^{13}$, como se estanques fossem, é importante consignar que num primeiro momento a atribuição desses direitos ao Homem foi uma reação aos abusos cometidos pelo Antigo Regime. O Absolutismo Monárquico, período de notórias restrições de direitos - pelo menos em sua concepção atual - promoveu a reação político-ideológica dos outrora marginalizados, a burguesia, com a erupção dos direitos de defesa em face do Estado.

Até mesmo pela sua origem histórica, refratária a um período de Poder semi-absoluto do monarca, as liberdades negativas foram desenhadas para proteger o indivíduo do Estado. $\mathrm{O}$ ideário iluminista não focava a proteção do indivíduo em face do indivíduo porque o próprio contexto em que estavam insertos tornavam a opressão estatal o principal obstáculo aos direitos individuais.

Com o passar do tempo e o processo gradativo de contrução de direitos sociais e de fraternidade e solidariedade - complementares entre si - o marco teórico iluminista foi sendo superado pela constatação de que o abuso ocorria não apenas do Estado contra os indivíduos, mas entre indivíduos. Os direitos fundamentais, que protegiam do arbítrio estatal, passaram a ser invocados em face dos particulares porque, novamente, o contexto histórico e social demandou uma nova concepção acerca dos direitos já construídos.

A expansão dos direitos fundamentais da dimensão vertical para a horizontal é, hoje, reconhecida como necessária, porquanto o Estado perdeu espaço para os particulares no protagonismo da ordem econômica e social. Embora a relevância do Poder Público seja

12 O tema é abordado em específico na obra: SARLET, Ingo Wolfgang. A eficácia do direito fundamental à segurança jurídica: dignidade da pessoa humana, direitos fundamentais e proibição do retrocesso social no direito constitucional brasileiro. Revista de Direito Social. Porto Alegre-RS Notadez, 2004.

13 É corrente a dimensionalização dos direitos fundamentais. Trata-se de processo de construção histórica, lenta e gradual, pela qual os diversos direitos em espécie se complementam. 
inegável, os abusos cometidos por particulares - promoção do trabalho análogo ao escravo, por exemplo - demandaram uma resposta jurídica adequada, esta encontrada na atribuição de efeitos horizontais a tais direitos.

O Estado não é mais um "Leviatã" - se é que algum dia o foi - que tudo pode para o bem e para o mal. Os entes públicos não são capazes de dar a resposta adequada às demandas do mundo atual, donde emerge a responsabilidade de outros atores para fazer frente a esses novos desafios.

O direito ao devido processo legal é exemplo claro dessa necessidade. A construção teórica objetiva frear o arbítrio estatal, condicionando a sujeição pelo Estado a um procedimento formal previamente definido. A construção de relações desiguais entre particulares expandiu esse marco principiológico, ao ponto de ser invocável também em relações privadas. Um associado não pode ser excluído de um clube sem que lhe seja outorgado o direito de defesa, por exemplo. A proteção contra a arbitrariedade em face do Estado se tornou universal, até mesmo contra particulares.

Essa exigência da atuação privada no âmbito da concretização dos direitos fundamentais é defendida pelos precursores do Estado de Responsabilidade Social. No meio do caminho entre o liberalismo e o intervencionismo radicais ${ }^{14}$, esse modelo prega a necessidade de ordem prática da atuação privada para tornar possível o enfrentamento dos novos e complexos problemas sociais que emergem com força cada vez maior até mesmo nos países desenvolvidos.

Para se ter uma dimensão dos problemas causados pela oligopolização da riqueza, existem, atualmente, 2153 (dois mil, cento e cinquenta e três) milionários no mundo, com uma renda total de US\$ 8,7 trilhões ${ }^{15}$. A lista é encabeçada por Jeff Bezos, da Amazon, com fortuna estimada em US\$ 131 bilhões.

Contas simplórias revelam o tamanho da desigualdade: o salário mínimo no Brasil é de $\mathrm{R} \$ 988,00$ (novecentos e oitenta e oito reais), ou seja, pela cotação atual, representa cerca

14 A maior ou menor intervenção do Estado na Economia é o eixo central de um sem-número de doutrinas econômicas. Trata-se de elemento nuclear no desenho das políticas públicas e de investimento muito mais do que um embate, a grosso modo, entre liberalismo total e irrestrito até o Estado Máximo. O Estado de Responsabilidade Social se encontra no meio desse caminho, pelo que entendemos ser uma doutrina valiosa para o enfrentamento de questões do novo milênio.

15 Dados da revista Forbes replicados pela revista Exame. Disponível em https://exame.abril.com.br/negocios/veja-quem-sao-os-mais-ricos-do-mundo-em-2019-segundo-aforbes/. Acesso em 19 de outubro de 2019. 
de US\$ 200 (duzentos dólares). Uma pessoa que recebe o salário mínimo precisaria trabalhar 655 milhões de meses - quase 55 milhões de anos - para atingir esse montante.

Não se questiona os méritos de quem atingiu tamanha fortuna. A redução dos privilégios de nascimento e sua substituição pelos privilégios do capital, no Estado burguês, não respondem mais às necessidades sociais. E, aqui, não se prega a redistribuição pura e simples de seu patrimônio, o esbulho do que, afinal, é dele, mas sim que se criem mecanismos de redistribuição de renda eficazes e, acima de tudo, voluntários. Em outros termos, a mudança da cultura empresarial é a essência de uma realidade transformadora, mais do que a tentativa de redistribuição por meio da tributação, a qual se demonstra deveras ineficiente no Brasil.

Bezos é um dentre os milhares de acionistas da Amazon. Isso quer dizer que, além dele, milhares de pessoas retiram ao menos parte de seu sustento do faturamento da companhia sem nenhum retorno para a sociedade. Usufruem apenas dos dividendos que a empresa distribui a partir do trabalho alheio - desta feita, uma retribuição maior das pessoas nessas condições, inclusive (mas não só) por tributos é essencial, sob a mesma lógica pela qual, por exemplo, se eleva a carga tributária sobre o capital financeiro.

O cenário se agrava porque a tecnologia, a par dos inúmeros empregos que vêm gerando neste século, tem promovido empresas com existência virtual, ou seja, com vastos lucros e pouca empregabilidade. Com isso, um dos principais aspectos da função social da empresa, a geração de emprego e renda, fica comprometida, redistribuindo o valor aos acionistas que em nada promovem para a consecução de externalidades positivas da atividade empresarial $^{16}$.

\section{Da horizontalidade como necessidade: como passar do liberalismo clássico para o fraternal}

Desta feita, acredita-se que imperativos de ordem prática exigem condutas positivas por parte das empresas a fim de que elas, para além das meras externalidades positivas decorrentes de sua atividade, passem a adotar condutas positivas no mercado concorrencial.

16 Entendemos que a função social da empresa é conceito bastante fluído. Adota-se corrente pela qual ela consistiria no reconhecimento das externalidades positivas da atividade empresárial. Há certo consenso, contudo, que ela decorre da conjugação do binômio livre iniciativa-justiça social, plasmado no art. 170 da Constituição Federal. Esse é o núcleo da função social da propriedade, o equilíbrio entre o lucro e a justiça social. 
A proteção e o incentivo à atividade empresarial caminham lado a lado com outros princípios e valores com a mesma envergadura constitucional, promovendo o temperamento do liberalismo tradicional que não mais responde às demandas da sociedade contemporânea. Uma economia, atualmente, não é capaz de prosperar sem que as engrenagens da iniciativa privada estejam rodando a pleno vapor17. Da mesma forma, o poder transformador do empresariado o coloca em posição privilegiada para promover a justiça social conclamada pela Constituição.

A propriedade, ao menos no sistema capitalista de produção, sempre foi protegida da arbitrariedade no ordenamento jurídico. O individualismo sublinhado pelas revoluções burguesas não respondeu às demandas sociais, como se percebeu com os eventos econômicos catastróficos ocorridos em 1929 e 2008 nos Estados Unidos18, donde a falta de regulação conduziu ao colapso do modelo econômico que se diz absenteísta.

Daí a funcionalização da empresa como forma de perenizar a própria atividade, na medida em que crises econômicas tais quais as relatadas, provocadas pelo individualismo exacerbado, inviabilizam a sustentabilidade do empreendimento tanto quanto uma pretensa coletivização dos meios produtivos, evidenciando a necessidade de proteger o indivíduo até dele mesmo quando se fala em atividade empresarial, já que o instinto egoístico calcado nas premissas liberais primitivas sempre exaltam o bem estar individual.

É dizer que, para sobreviver, não basta cuidar de si mesmo. Deve-se dar ao menos uma parte para a coletividade, para além das taxas e impostos (TOMEI, 1984), enquanto esta coletividade pode e deve atuar para que ele não sofra com sua própria ganância, reconhecendo o necessário papel transformador do empresariado.

O lucro, tal qual já se ressaltou, é o principal combustível para a atividade empresarial (caso contrário, seria filantrópica ou governamental). Embora seja esse o interesse direto do empreendedor, talvez o único, deve o ordenamento jurídico incentivar e fiscalizar para que na busca pelo lucro ele não assassine outros valores constitucionais de igual envergadura, para que, afinal, sua atividade tenda à promoção da dignidade da pessoa humana.

17 PIOVESAN (2007, p. 34) exemplifica com notória simplicidade: "No que se refere ao setor privado, há também a necessidade de acentuar sua responsabilidade social, especialmente das empresas multinacionais, na medida em que constituem as grandes beneficiárias do processo de globalização, bastando citar que das 100 (cem) maiores economias mundiais, 51 (cinqüenta e uma) são empresas multinacionais e 49 (quarenta e nove) são Estados nacionais".

18 Julgamos que a desregulação dos mercados não se confunde com liberalismo; todavia, é sintomático que duas das maiores crises econômicas mundiais tenham ocorrido nos Estados Unidos exatamente pela regulação inexistente ou ineficiente do mercado. 
O ordenamento jurídico adota uma série de sanções para as empresas que atuam em contrariedade à concretização de direitos fundamentais, outorgando, por exemplo, a pena de expropriação para propriedades que utilizem trabalho análogo ao escravo.

É no estabelecimento de sanções premiais que o Estado pode encontrar a solução para a problemática. A criação de mecanismos de incentivo à atividade empresarial realizar, por esponte própria, os fins almejados pelo ordenamento jurídico em detrimento de lucro imediato (embora essas sanções objetivem, justamente, ampliar o lucro empresarial). A sanção premial aos agentes filantropos é um dos meios eficientes, eficazes e efetivos para o Estado alocar recursos de maneira ótima em áreas de interesse público19.

O Direito não precisa, somente, atuar punindo agentes que não atuem contrariamente à ordem jurídica, mas pode e deve ter elementos de premiação de quem promove atitudes positivas a serem incentivadas. Como já afirmado, a tributação é meio coercitivo com pouca ou nenhuma eficácia neste mister.

Muitas empresas já perceberam que filantropia é um negócio lucrativo. Não se trata de arquitetar de forma maquiavélica20 que os fins justificariam os meios: se a real motivação é a ampliação de receitas, pouco importa, se isso se prestar à efetivação de direitos21. As ações de responsabilidade social são amplamente propagandeadas porque ampliam os lucros empresariais, melhoram a imagem das empresas, e não porque elas subitamente perceberam seu papel dentro da sociedade de risco. Caso não fossem lucrativas, tais atividades certamente cessariam, porque sem incentivos, ainda que egoísticos, não seriam uma prioridade para o empresariado.

É dentro desse contexto que ações voltadas, efetivamente, para a responsabilidade social ganham relevo. Mais do que jogadas de marketing, elas são essenciais para o florescimento das comunidades em que as grandes corporações atuam, favorecendo o ambiente de negócios e a visão que se tem dessa organização22.

19 Entende-se que a diferença entre direitos e garantias demanda uma atenção mais detida, já que não há garantia à sustentabilidade empresarial, embora exista o correspondente direito. Nesse sentido é que o Estado deve adotar medidas efetivas para que tais direitos transbordem da mera retórica.

20 A expressão atribuída ao filósofo Nicolau Maquiavel jamais foi dita ou escrita por ele; porém, o bordão é repetido se valendo da sua autoridade.

21 A atual conjuntura empresarial torna improvável que um argumento seja tão eficaz quanto a promessa de retorno financeiro, já que a direção das grandes empresas são influenciadas por um mercado sedento por dividendos.

22 A publicação "Empresas e Direitos Humanos na Perspectiva do Trabalho Decente" enumera várias ações de responsabilidade social com grande impacto para a comunidade e para as empresas que as carreiam. Disponível em https://www.ethos.org.br/wp-content/uploads/2012/12/04_Empresas-e- 
Segundo TOMEI (1984, p. 192), os defensores do investimento social se lastreiam no ganho de imagem pública e no retorno de longo prazo para promoção das ações sociais, ou seja, que se trataria de investimento e não despesa para o empresariado ${ }^{23}$.

A toda evidência, o investimento no social é imperativo de ordem prática que promove ganhos para a própria empresa, ou seja, trata-se de círculo virtuoso em que todos saem ganhando. Não se trata de exigir de pequenas ou modestas empresas que atuem nesta seara e sim que os grandes conglomerados, com seu potencial transformador, atuem na direção de um Estado de Responsabilidade Social.

Retornando ao exemplo de Jeff Bezos e da Amazon, a empresa faturou "apenas" US\$ 177 bilhões em 2018. A maior empresa do mundo em faturamento, a Walmart faturou US\$ 500 bilhões $^{24}$. Parece crível que uma parte desse valor revertesse em benefícios sociais - não em Impostos - e sim por ações efetivas e contundentes.

As normas de preservação socioambiental, mais do que a supremacia do interesse público sobre o privado, representam o trunfo da solidariedade e da ampla proteção do indivíduo, que deve ser protegido de si mesmo, da cegueira que a ganância e a vontade de lucrar podem lhe provocar25. Da mesma forma, é possível que normas obriguem o indivíduo a se proteger, como a obrigatoriedade do uso do cinto de segurança - afinal, negligenciar o social traz lucro imediato, mas insustentabilidade para a empresa e para a sociedade no médio e longo prazos.

O Estado deve incentivar a funcionalização do Direito Privado sob balizas éticas - daí nosso entusiasmo com sanções premiais -, que privilegiem a dignidade da pessoa humana e a

Direitos-Humanos-na-Perspectiva-do-Trabalho-Decente-\%E2\%80\%93-Marco-Referencial.pdf . Acesso em 20 de outubro de 2019.

23 Afirma a autora: "Este conceito pressupõe que a sociedade espera que as empresas, visando um retomo a longo prazo, realizem uma variedade de benefícios sociais. Assim, a empresa mais sensível às necessidades da comunidade terá como resultado uma comunidade melhor, onde será mais fácil a 'própria gerência dos negócios. Com isto, por exemplo, o recrutamento de pessoal será facilitado, a qualidade da mao-de-obra se elevará, as taxas de rotatividade e absenteísmo se reduzirão etc. Este processo de melhoria social geraria, então, ciclos do gênero: numa esfera macro, os benefícios sociais a comunidade acarretariam uma redução da propriedade, melhoria na qualidade de vida, aumento do consumo etc. Este argumento pode ser entendido em diversas direções, demonstrando que uma sociedade melhor gera um ambiente melhor para as empresas".

24 Dados da revista Fortune reproduzidos pela Exame. Disponível em https://exame.abril.com.br/negocios/as-20-maiores-empresas-do-mundo-segundo-a-fortune/ . Acesso em 19 de outubro de 2019.

25 Outro filósofo a tratar sobre o tema foi Robert Nozick. Em sua obra Anarchy, State, and Utopia, defende que esse dever de proteção inexiste, devendo prevalecer a autodeterminação dos indivíduos em um contexto de Estado Mínimo. 
pacificação social, ainda que signifique proteger o indivíduo dele mesmo, mitigando sua liberdade. Assim sintetiza GRAU (2003, p. 197-198)26.

O mero cumprimento de deveres legais, como a não contratação de trabalhadores em condições análogas à escravidão, não se presta mais às exigências do novo milênio. É necessário uma política de remuneração e diversidade condizente com os desafios enfrentados pelos empregados, aliada a um sólido repertório de responsabilidade social que ultrapasse as externalidades da função social da empresa, para que se obtenham os benefícios almejados e necessários.

Deve-se ressaltar que o respeito a tais caracteres promove um ambiente concorrencial mais sadio e duradouro, com a fiscalização horizontal das regras de conduta e compromissos conjuntos com a sociedade e o meio ambiente.

Quando um empreendedor adota determinada conduta que afeta o ambiente concorrencial, a exemplo do dumping social, ele pressiona todo o setor a adotar condutas de mesmo jaez, sob pena da atividade se tornar pouco competitiva. $\mathrm{O}$ efeito cascata provocado pela mimetização das boas e más práticas empresariais não pode ser desprezado. A sociedade precisa que a empresa atue segundo sua função social para promover o bem de todos, inclusive dela mesma, pois ela é a fonte produtora de riqueza, o vetor das transformações sociais. O (des)cumprimento por parte de uma influencia decisivamente no comportamento de todas.

Assim, o mimetismo ocorrerá quando as maiores empresas se unirem para tornar o planeta habitável - afinal, não há consumidores em Marte ou Plutão. É neste mundo que desenvolvem seus negócios e é parte de sua responsabilidade cuidar deles, em conjunto e coordenadamente. Se determinada empresa de petróleo, por exemplo, acredita que será prejudicada no social, uma joint venture entre todas as participantes do mercado oligopolizado resolveria esse problema, pois não haveria nenhum prejuízo competitivo.

26 Aduz o autor: "O desenvolvimento supõe não apenas o crescimento econômico, mas sobretudo elevação do nível cultural-intelectual comunitário e um processo, ativo, de mudança social. Daí porque a noção de crescimento pode ser tomada apenas e tão-somente como uma parcela da noção de desenvolvimento. O desenvolvimento, como já apontava Schumpeter (Teoría del Desenvolvimiento Econômico. Trad. de Jesús Prados Ararte, Fondo de Cultura Económica, México, 1967, p. 74), se realiza no surgimento de fenômenos econômicos qualitativamente novos - isto é, de inovação conseqüentes à adoção de novas fontes de matéria prima, de novas formas de tecnologia, de novas formas de administração da produção, etc. (...) Garantir o desenvolvimento nacional é, tal qual, construir uma sociedade livre, justa e solidária, realizar políticas públicas cuja reivindicação, pela sociedade, encontra fundamentação neste art. $3^{\circ}$, II. O papel que o Estado tem a desempenhar na perseguição da realização do desenvolvimento, na aliança que sela como setor privado, é, de resto, primordial". 
Parece-nos inegável que, ao desrespeitar uma norma justrabalhista, o ofensor não ataca somente o direito daqueles trabalhadores. Ele agride, igualmente, seus concorrentes e o mercado, aferindo lucros artificiais em detrimento dos demais atores do mercado. Desta feita, o cumprimento e a fiscalização cruzada entre as empresas é instrumento de seu próprio interesse, pois pressiona todos a cumprirem as regras determinadas pela legislação.

Os ganhos internos também são sentidos pelas empresas. A diversidade é elemento crucial nas empresas mais eficientes e eficazes, ampliando a inovação no trabalho. Encampar esta pauta implica na contratação de minorias, como pessoas com deficiência, para cargos importantes e de relevo, promovendo ganhos de eficiência para a própria empresa. Não se trata de caridade e sim de necessidade dentro do mercado competitivo.

De todo modo, o ordenamento jurídico brasileiro possui bases para a criação de mecanismos de incentivo à concretização dos direitos fundamentais efetivos, que não sejam meras ações de marketing. Basta a visão ao empreendedor estar em sintonia com as exigências do bem comum.

A problemática da concretização dos direitos fundamentais vai muito além do desígnio de tais direitos na ordem jurídica. Medidas efetivas, como a construção de um ambiente de responsabilidade social, são elementos nevrálgicos para a construção de políticas públicas e privadas efetivas.

A atividade empresarial, para além das externalidades positivas da atividade, como geração de emprego e renda, circulação de riqueza, pode e deve atuar, já que a eficácia horizontal dos direitos fundamentais assim lhe exige. Os mecanismos de compatibilização desta necessidade com a realidade e os instrumentos jurídicos disponíveis, bem como da ideologia dominante, tornam este horizonte distante, enquanto milhões ainda morrem de inanição para que uns poucos podem se esbaldar. Neste sentido é que a atividade empresarial é essencial à concretização dos direitos fundamentais em um Estado que necessita cambiar para a responsabilidade social.

Deve-se ressaltar que o direito fundamental proposto27, uma espécie de "solidariedade empresarial", é reconhecido na ordem internacional e, como tal, há de ter prevalência sobre as normas internas em sentido contrário. É dizer: há uma tendência de se reconhecê-lo

27 A diferença entre direitos humanos e direitos fundamentais é o escopo: aqueles designam os direitos inerentes ao ser humano na ordem internacional, enquanto estes recebem a nomenclatura com a internalização. Tal discussão é mera celeuma acadêmica, já que a terminologia não afasta a inexorável necessidade de proteção. 
mundialmente, donde, da universalização dos direitos humanos, entende-se que não pode haver norma a afastá-la. Por sinal, como será visto, em havendo tratados internacionais, estes terão força supralegal28, tornando inaplicáveis disposições em sentido contrário - como a Lei de Liberdade Econômica.

\section{Da temática no plano internacional}

$\mathrm{Na}$ ordem internacional, há uma série de compromissos travados entre as nações reconhecendo essa necessidade: Diretrizes para Empresas Multinacionais Declaração da Organização para a Cooperação e o Desenvolvimento Econômico (1976), a Declaração Tripartita de Princípios sobre Empresas Multinacionais e Política Social da Organização Internacional do Trabalho (1977), o Pacto Global da ONU (2000) e os Princípios Orientadores sobre Empresas e Direitos Humanos da ONU (2011). Esta última é a mais contundente sobre o tema, pois correlaciona diretamente temáticas até então separadas.

As tratativas sobre Direitos Humanos e Empresas, aprofundada em 2011, são objeto específico de Relatório da Organização das Nações Unidas29 em que a situação no Brasil é retratada. Naquele documento, de 2015, constata-se que há muito a se percorrer ainda, no País, para que se fale em Direitos Humanos e Empresa.

$\mathrm{Na}$ apresentação daquele documento, redigida pela subprocuradora da República Deborah Duprat, afirma-se que essa correlação, cujo marco defendemos que se deu, especificamente, em 2011 na ONU com “Os princípios Orientadores Sobre Empresas e Direitos Humanos"30 não constituem nova dimensão de Direitos Humanos e sim uma faceta desses direitos quando em interface com empresas.

28 Nesse sentido é que entendemos inconstitucional a Lei de Liberdade Econômica, veiculada neste ano, que veda quase que em absoluto a intervenção estatal. A Carta não adota o ultraliberalismo econômico e, por isso, não pode uma lei fazê-lo. E, se não inconstitucional, é inaplicável, já que as normas veiculadoras de direitos humanos tem, no entender do Supremo Tribunal Federal, caráter supralegal. Há intenso debate sobre o caráter destas normas; prefere-se, porém, no escopo deste trabalho, adotar o posicionamento judicial.

29 ORGANIZAÇÃO DAS NAÇÕES UNIDAS. Recomendações do Grupo de Trabalho da ONU sobre Empresas e Direitos Humanos: Status da Implementação Pelo Governo e Empresas. Brasil: 2015.

30 Afirma a subscritora naquele texto introdutório (p. 02) que "É preciso ver nos "princípios Orientadores", em países cujas constituições têm a sua identidade estabelecida a partir de amplo catálogo de direitos fundamentais, uma instrumentalidade diversa. De um lado, organizam o tema de modo a possibilitar um controle social ampliado; de outro, mobilizam atores importantes da sociedade civil para essa tarefa de vigilância e denúncia". 
A visão da ONU ainda é centrada no cumprimento da função social da empresa, no respeito ao trabalho digno, à vedação ao trabalho infantil, análogo ao escravo, dentre outros. Trata-se de concepção mais acanhada do que a proposta neste trabalho, no qual se defende a adoção ampla, as posturas positivas das empresas e não o mero aceite da legislação. Até por isso, naquele texto prefacial, a autora afirma que a questão é mais cultural do que legislativa31.

Há muita resistência, até mesmo por questões ideológicas, para a aceitação desse paradigma de atuação empresarial. Os privilégios do capital colocam os detentores do poderio financeiro em posição determinante na agenda internacional. Essa dificuldade é relatada por RUGGIE (2017, p. 19), um dos precursores do ideario na ONU, sob o pretexto de que estariam sendo privatizadas as funções do Estado.

Acredita-se que o papel do Estado ultrapassa a fiscalização das condições de trabalho, à repressão do trabalho infantil e ao trabalho análogo de escravo. Por evidente, tais funções são relevantes. Não se trata de jogo de "gato e rato" em que o empreendedor tenta burlar as leis e o Estado o sancionar, se o flagrar em alguma irregularidade. Deve haver conjugação dos esforços para erradicar essas formas de trabalho degradante e, para além disso, para a promoção do bem-estar das partes vulneráveis.

As relações jurídicas marcadas pela desigualdade exigem que a fiscalização caminhe lado a lado com a conscientização da parte dominante - e, no mais das vezes, trata-se de uma empresa na condição de dominância, inclusive em relação ao Estado.

Ainda há dificuldade em estabelecer regras internacionais claras sobre o tema e que obriguem os atores estatais32 a atuarem de forma contundente nesta seara. Conforme OLIVEIRA (2018, p. 14), há diversos espectros de responsabilidade empresarial com relação aos Direitos Humanos, os quais ainda sofrem com a falta de concretização pelos Estados. A atribuição de efeitos jurídicos a tais tratados é curial para a ampliação do papel do empresariado, de forma voluntária (e não imposta) na concretização dos direitos humanos.

31 Consta do documento (p. 02) que "A sociedade brasileira segue refém de projetos de desenvolvimento de cunho oligárquico, onde as múltiplas percepções de mundo e de vida são desconsideradas, e de uma compreensão de que as empresas, motores desse modelo de desenvolvimento, devem ser preservadas de maiores constrangimentos. Não nos falta lei, mas sim uma cultura de direitos humanos que a todos alcança, de modo indistinto".

32 Essa dificuldade decorre, no nosso sentir, do amálgama cultural presente na ONU, o que dificulta qualquer consenso quanto à aplicabilidade direta e imediata dos direitos humanos, de forma cogente, aos Estados. Ainda que se trate, ao nosso sentir, de imperativo de ordem prática, obstáculos ideológicos (mais até do que jurídicos) tornam difícil a missão de abarcar os direitos humanos nas empresas para além do mero cumprimento da legislalção ou de um patamar mínimo civilizatório. 


\section{CONCLUSÃO}

A gravitação do poder político, econômico e financeiro em torno das grandes corporações exigem compromissos sociais diferenciados para viabilizar não apenas a justiça social, mas a própria subsistência do ser humano enquanto espécie. Os Estados, por si só, não são capazes de resolver as mazelas do mundo moderno.

Para além de uma visão mesquinha, o Estado de Responsabilidade Social conclama pela adoção de posturas ativas dos atores privados para a concretização dos direitos fundamentais, tendo em vista seu inegável poder transformador. Trata-se de imperativo de ordem prática de que dependem todos aqueles que não podem, por seu próprio esforço ou do Estado, terem garantidos os seus direitos.

No primeiro tópico deste artigo, definiu-se como a concretização de direitos fundamentais é dever de todos, inclusive das sociedades empresárias. Estas detém boa parte do poder econômico e político, necessário à realização das mudanças sociais, que devem ser fomentadas e não impostas para que estes agentes, com enorme potencial transformador, ajam positivamente.

No segundo tópico, fundamentou-se a premissa supra juridicamente a partir da reconhecida eficácia horizontal dos direitos fundamentais. Os preceitos veiculados contra a arbitrariedade se aplicam em relações particulares e criam direitos e deveres recíprocos, os quais denotam a existência de obrigações relativas à função social da empresa.

No terceiro tópico, concluiu-se que essa transformação no papel da empresa, além de necessária, marca a transição de um Direito voltado ao indivíduo para outro voltado à coletividade, com fundo marcantemente social. É uma mudança de paradigma salutar pois compatibiliza melhor os interesses de todos os atores sociais.

No quarto e último tópico, demonstrou-se que o recrudescimento da função social da empresa e da sua atuação transformadora tem sido objeto de discussão e normatização internacionalmente, conferindo ainda maior importância à discussão em nível nacional.

A visão internacional acerca do tema ainda se liga muito à concretização de direitos básicos, ao mínimo existencial e ao cumprimento da legislação, quando, na verdade, encampa-se uma visão mais ampla em que se exorta à participação ativa das empresas na concretização dos direitos fundamentais, fazendo-o não somente pela circulação de riqueza, 
pelo cumprimento de sua função social, mas indo além, promovendo condutas positivas que estimulem ganhos para toda a comunidade em que atuam.

A existência de um Estado de Responsabilidade Social emerge cada vez mais como uma resposta necessária às demandas sociais, em um contexto que o poder econômico dos grandes conglomerados tem suplantado muitas economias nacionais, denotando que a mudança de postura é essencial à sobrevivência comunitária.

\section{REFERENCIAS}

BARROSO, Luis Roberto. A Ordem Econômica Constitucional e os Limites à Atuação Estatal no Controle de Preços. Revista Eletrônica de Direito Administrativo Econômico. Mai/Jun/Jul 2008. Disponível em http://bibliotecadigital.fgv.br/ojs/index.php/rda/article/view/47240. Acessado em 04 de outubro de 2019.

DURÃO, Pedro. Direito Empresarial Objetivo. $1^{\text {a }}$ Edição. Aracaju: DireitoMais, 2018.

ENCICLOPÉDIA JURÍDICA PUC-SP, tomo IV (recurso eletrônico) : direito comercial / coords. Fábio Ulhoa Coelho, Marcus Elidius Michelli de Almeida - São Paulo: Pontifícia Universidade Católica de São Paulo, 2018. Disponível em https://enciclopediajuridica.pucsp.br> . Acesso em 29 de abril de 2019.

EXAME. Reportagem "Veja quem são os mais ricos do mundo em 2019”. Disponível em https://exame.abril.com.br/negocios/veja-quem-sao-os-mais-ricos-do-mundo-em-2019segundo-a-forbes/ . Acesso em 19 de outubro de 2019.

EXAME. Reportagem “As 20 maiores empresas do mundo segundo a Fortune”. Disponível em https://exame.abril.com.br/negocios/as-20-maiores-empresas-do-mundo-segundo-afortune/ . Acesso em 19 de outubro de 2019.

GRAU, Eros Roberto. A ordem econômica na Constituição de 1988. $8^{\text {a }}$ ed. São Paulo: Malheiros, 2003.

INSTITUTO ETHOS. Empresas e Direitos Humanos na Perspectiva do Trabalho Decente Marco de Referência. São Paulo: Ethos. 2011. Disponível em https://www.ethos.org.br/wpcontent/uploads/2012/12/04_Empresas-e-Direitos-Humanos-na-Perspectiva-do-Trabalho-

Decente-\%E2\%80\%93-Marco-Referencial.pdf . Acesso em 20 de outubro de 2019.

NOZICK, Robert,.1974 [ASU], Anarchy, State, and Utopia, New York: Basic Books. 
OLIVEIRA, Carina Costa de. Manual sobre direitos humanos e empresas transnacionais na América Latina - Dados eletrônicos. - Goiânia : Gráfica UFG, 2018. ORGANIZAÇÃO DAS NAÇÕES UNIDAS. Recomendações do Grupo de Trabalho da ONU sobre Empresas e Direitos Humanos: Status da Implementação Pelo Governo e Empresas. Brasil: 2015.

PIOVESAN, Flávia. Empresa e Direitos Humanos. $1^{\text {a }}$ Edição. Ed. Jus Podium: São Paulo, 2018.

RUGGIE, John Gerard. Quando negócios não são apenas negócios: as corporações multinacionais e os Direitos Humanos. São Paulo: Planeta Sustentável, 2013.

SAYEG, Ricaddo Hasson; BALERA, Wagner. O capitalismo humanista. Filosofia humanista de direito econômico. Rio de Janeiro: KBR Editora Digital, 2011.

SARLET, Ingo Wolfgang. Dignidade da pessoa humana na Jurisprudência do Supremo Tribunal Federal. In Interpretação constitucional no Brasil / coordenação: Renato Siqueira De Pretto Richard Pae Kim e Thiago Massao Cortizo Teraoka. São Paulo: Escola Paulista da Magistratura, 2017.

A eficácia do direito fundamental à segurança jurídica: dignidade da pessoa humana, direitos fundamentais e proibição do retrocesso social no direito constitucional brasileiro. Revista de Direito Social. Porto Alegre-RS Notadez, 2004.

SUPREMO TRIBUNAL FEDERAL. ADIn 4650. Disponível em https://stf.jusbrasil.com.br/jurisprudencia/23086639/acao-direta-de-inconstitucionalidade-adi4650-df-stf. Acesso em 29 de outubro de 2019.

TOMEI, Patrícia. Responsabilidade social de empresas: análise qualitativa da opinião do empresariado nacional. Rev. adm. empres. vol.24 no.4 São Paulo Oct./Dec. 1984. Disponível em http://www.scielo.br/scielo.php?script=sci_arttext\&pid=S0034-75901984000400029. Acesso em 29 de outubro de 2019.

WARDE JUNIOR, Walfrido Jorge. A empresa pluridimensional : empresa política e lobby. Revista do advogado, São Paulo, a.28n.96 (Jul.2008), p.137-145. 